\title{
Lukács e Marx contra o "ecologismo acrítico": por uma ética ambiental materialista "
}

\author{
João Leonardo Medeiros ** \\ Eduardo Sá Barreto ${ }^{* * *}$
}

\begin{abstract}
Resumo
$\mathrm{O}$ artigo desenvolve uma crítica às concepções conservadoras da ecologia, partindo de uma reinterpretação da teoria do valor de Marx baseada na obra de G. Lukács. São enfatizadas, nesta crítica, as implicações dessas concepções para o plano da ética.
\end{abstract}

Palavras-chave: Ecologismo; Ética ambiental; Sustentabilidade; Moral; Teoria do valor.

\section{Abstract \\ Lukács and Marx against "uncritical ecologism": for a materialist environmental ethics}

The paper intends to develop a critique of the conservative conceptions on ecology from the standpoint of a reinterpretation of Marx's theory of value based on the work of G. Lukács. This critique put particular emphasis on the implications of such conceptions for the domain of ethics.

Keywords: Ecologism; Environmental ethics; Sustainability; Moral; Theory of value.

JEL Q590, B510.

\section{Introdução}

É seguro afirmar que a preocupação com a iminente crise ambiental é, hoje, generalizada. Além dos desastres ambientais provocados pelos seres humanos - como os casos de derramamento de petróleo do Amoco Cadiz na Costa Francesa e do Exxon Valdez no Golfo do Alasca, o desmatamento da Amazônia, o acidente nuclear em Fukushima -, a intensidade e o número de eventos extremos, ditos naturais, exibem cada vez mais seu caráter antropogênico. Não surpreende, dessa forma, que a temática ambiental venha provocando reflexões em diversos setores da sociedade.

Ainda que restritas em número e em capacidade de mobilização, é possível identificar formulações teóricas dos problemas ambientais que se inspiram em análises radicalmente críticas da sociedade (das quais privilegiaremos aquelas emitidas a partir do campo marxista). Autores como Foster (2002) e Burkett (1999) já estabeleceram, em nosso juízo, com sucesso, o vínculo entre a dinâmica própria

\footnotetext{
* Trabalho recebido em 23 de março de 2011 e aprovado em 29 de novembro de 2011.

${ }^{* *}$ Professor Adjunto do Departamento de Economia da Universidade Federal Fluminense (UFF), Niterói, RJ, Brasil. E-mail: jlgmedeiros@vm.uff.br.

*** Professor do Departamento de Economia e Finanças da Universidade Federal de Juiz de Fora (UFJF), Juiz de Fora, MG, Brasil. E-mail: eduardo.barreto@ufjf.edu.br.
} 
da formação socioeconômica vigente e os inúmeros fenômenos de degradação ambiental. Mesmo assim, continua a prevalecer, no debate sobre o tema, o que chamaremos de ecologismo acrítico (ou presentista ${ }^{1}$ ): o ecologismo (estudo científico da relação entre a vida social e o ambiente natural) que se distingue pela pretensão de superar os problemas ambientais no interior da formação social em que vivemos, a sociedade regida pelo capital.

Nosso objetivo, neste artigo, é chamar a atenção para uma debilidade fundamental do ecologismo acrítico: o desdobramento das preocupações ambientais em preceitos éticos abstratos. O problema, neste caso, reside no fato de que a ética em que se resolvem as teorias do ecologismo acrítico é simplesmente postulada, sem que seja investigada a sua relação com os pressupostos objetivos da prática social que pretende realizar os valores que lhe dão forma. Buscaremos demonstrar, ao longo das próximas seções, que valores não são entidades meramente subjetivas que possam ser enunciadas de modo arbitrário, de maneira que o ecologismo acrítico padece de um problema de origem.

Mais detidamente, o ponto a sustentar é que os valores são determinações objetivas da prática social, cujas condições de realização podem e devem ser investigadas. Por outro lado, procuramos defender a concepção, inspirada numa releitura da crítica social de Marx, de que, na sociedade capitalista, todos os valores, inclusive aqueles pressupostos na "ética ambiental" implicada pelo ecologismo acrítico, têm sua realização subordinada a uma espécie de ética objetiva: a ética do capital. Isso faz com que o problema teórico do ecologismo acrítico adquira uma expressão prática: o erro teórico de postular valores convertese num problema de realização porque os valores postulados se mostram incompatíveis com os valores que caracterizam a sociedade do capital no plano ético-moral.

O argumento acima delineado é desenvolvido em três seções, além da conclusão. A seção a seguir apresenta uma síntese bastante geral das principais ideias, normalmente associadas à noção de desenvolvimento sustentável, que aqui reunimos sob o termo de ecologismo acrítico. Na segunda seção do artigo, buscamos apoio em Lukács para demonstrar que a ética, a moral e os juízos de valor, embora envolvam nitidamente a subjetividade humana, possuem uma raiz objetiva insuperável. Na terceira seção, recorremos a Marx, numa interpretação obviamente não exaustiva, para defender a noção de que a "dominação abstrata" da

(1) Consideramos presentista a análise da realidade presente carente de perspectiva histórica, isto é, a análise que, explícita ou veladamente, considera, como limite último das práticas humanas, as possibilidades já efetivadas no presente. Empregamos, portanto, o termo no mesmo sentido que Netto (2002, p. 53) e Fontes (1996, p. 34). 
humanidade pelo capital descrita em sua principal obra envolve um momento ético: a subordinação dos objetivos humanos ao valor (tempo de trabalho) ${ }^{2}$.

\section{0 ecologismo acrítico e a hipervalorização da subjetividade}

A teoria social em geral e o seu subconjunto que aborda as questões ambientais, via de regra, recorrem, como fundamento teórico e como atestado de prestígio, às teorias econômicas. Quando se trata de representar aquilo que denominamos "ecologismo acrítico", portanto, é no pensamento econômico voltado para as questões ambientais que se encontra o material bruto. É preciso reconhecer, no entanto, que, no interior da Economia, há um corte significativo quanto à forma de entender as questões relacionadas à degradação do meio ambiente. Há uma linha ortodoxa, que atribui à ausência de determinados incentivos de mercado a causa dos principais problemas ambientais. A construção teórica, nesse caso, volta-se à justificativa e sugestão de mecanismos (incentivos) que facultem a extensão da lógica do mercado a situações nas quais ele ainda não opera claramente ou de modo eficiente. Sendo adotados os incentivos corretos, acredita-se, os indivíduos redirecionariam suas práticas perdulárias em um sentido sustentável ${ }^{3}$.

Ainda que a abordagem acima predomine no interior da ciência econômica, existe uma corrente que procura tratar da temática ambiental em termos alternativos. Essa linha se distingue pela defesa da produção e do consumo conscientes, baseados numa nova ética. Em outros termos, a resolução da crise ambiental estaria assentada sobre uma transformação ética generalizada que teria diretamente como foco as práticas individuais.

A análise que realizaremos ao longo deste artigo concentra-se nessa segunda vertente, ainda que as críticas aqui realizadas possam ser também estendidas de modo integral, com as devidas mediações, às formulações ortodoxas. Tal opção não se justifica primordialmente no campo teórico, um campo em que, por definição, as concepções ortodoxas são dominantes, mas sim no domínio mais amplo das práticas sociais. Nesse plano da prática social - em particular, na política ambiental e na formação de um senso ecologista comum -, é facilmente

(2) "Dominação abstrata" é a expressão empregada por Postone (1993, p. 3) para descrever a forma de dominação que caracteriza a sociedade do capital: a dominação da humanidade pela lógica semi-automática de valorização do valor (reprodução capitalista).

(3) Essa primeira versão do ecologismo é usualmente denominada "economia ambiental". Seus principais articuladores são Hotelling (1949), Coase (1960), Solow (1976), Pearce e Turner (1990), Costanza et al. (1997), Stern (2007), entre outros. As correntes que elaboram uma crítica a essa versão normalmente se alinham a formulações do que se denomina "economia ecológica", que trataremos na sequência do texto. 
constatável a maior influência das abordagens alternativas ${ }^{4}$. Ademais, nessa segunda versão do ecologismo acrítico, a ética ambiental é formulada de modo aberto e consciente em lugar de ser simplesmente assumida, como na vertente ortodoxa.

Iniciemos pela recomposição dos antecedentes do ecologismo acrítico e do contexto que favoreceu seu desenvolvimento. Quanto aos antecedentes, podemos recorrer à síntese de Smith (1996), na qual o autor aponta que o questionamento do crescimento econômico como um fím em si mesmo já está presente nas formulações de pensadores como Sismondi, Ruskin, Hobson e Tawney. O autor recorre, por exemplo, à noção de bem-estar orgânico de Hobson: um estado no qual uma série de valores não econômicos (artísticos, religiosos, etc.) são levados em consideração na atividade econômica. Na opinião de Smith (1996, p. 203-204), esse estado deveria ser almejado como fim da produção, em oposição ao objetivo, ilimitado a priori, de expansão da produção, visando o lucro. $\mathrm{O}$ autor recorre à Sismondi, fazendo uso do conhecido conto de Gandalin (o aprendiz de feiticeiro), para destacar a possibilidade de que a utilização intensiva de um maquinário cada vez mais eficiente no processo produtivo terminasse por inundar o meio ambiente com uma produção incessante e, em boa medida, supérflua (Smith, 1996, p. 189190). Para Smith, o impulso pela ampliação irrestrita da produção (e a degradação ambiental que a acompanha) está intimamente associado a um determinado conjunto de valores sem conexão direta com o que seriam as reais necessidades dos seres humanos. Por sustentar tais valores, os indivíduos conduziriam a produção social num sentido antiecológico, perdendo a oportunidade de economizar recursos ao utilizar os avanços tecnológicos de forma perdulária. Small e Jolland (2006) retomam essa ideia ao apresentarem dois mitos gregos para tipificar de que maneira o desenvolvimento econômico, tomado como um fim em si mesmo, pode criar problemas ambientais irreversíveis.

Com o mito de Prometeu, os autores procuram representar o domínio da humanidade sobre a natureza, facultado pelo progresso tecnológico. Para representar os riscos envolvidos em tal progresso, isto é, a possibilidade de liberar males desconhecidos e desencadear uma sucessão de eventos com efeitos inesperados e potencialmente adversos, os autores recorrem ao mito de Pandora. $\mathrm{O}$ acesso à dominação da natureza pelos seres humanos possuiria, enfim, um caráter dual de facultar maior conforto e simultaneamente possibilitar a transformação da natureza de forma imprevisível e por vezes até irreversível (Small; Jolland, 2006, p. 348-349).

(4) Para atestá-lo, basta contrastar as referências que representam classicamente cada uma das formulações. De um lado, estão economistas de ofício, em geral desconhecidos pelo grande público, de outro, instituições como o Greenpeace e articulistas políticos muitíssimo influentes, como Al Gore. 
Como nos mostra Smith, a preocupação em torno da interação estabelecida entre sociedade e natureza já se faz presente em formulações econômicas do século XIX e início do século XX. O tratamento sistemático dessas ideias ocorre, contudo, a partir da década de 1970. A Conferência das Nações Unidas sobre o Ambiente Humano, realizada em Estocolmo em 1972, é normalmente reconhecida como o primeiro momento em que as questões ambientais entram efetivamente na agenda internacional (Sachs, 2002, p. 48). Porém, o principal marco para o reconhecimento formal da urgência em atingir uma sociedade ambientalmente sustentável é a publicação, em 1987, do relatório intitulado Nosso Futuro Comum (CMMAD, 1991), posteriormente reforçado pelo encontro de cúpula do Rio de Janeiro em 1992.

Desde então, um amplo conjunto de propostas conquistou espaço, amparadas pelo crescente entendimento científico dos impactos humanos sobre a deterioração das condições da vida na Terra. Isso se manifesta na expansão do número de projetos inspirados em uma (alegada) responsabilidade ambiental e numa tendência de alteração de hábitos dos consumidores, e até de alguns nichos do setor produtivo. Podemos situar, no assim chamado terceiro setor, alguns dos exemplos mais representativos da esperança que é depositada na mudança de hábitos individuais.

No documento intitulado How to Save the Climate (Greenpeace, 2007), por exemplo, encontramos uma extensa lista de pequenas modificações a serem realizadas no cotidiano para reverter o processo de aquecimento global. As palavras de ordem são "Fique mais bem informado!", "Comece com você mesmo!", “Tente convencer outras pessoas a fazer o mesmo!” (Greenpeace, 2007, p. 10). Isso não difere muito da campanha ambientalista recente de Al Gore. Segundo o ex-vice-presidente norte-americano, diante da crise ambiental:

[...] é fácil se sentir massacrado e impotente, sem acreditar que os esforços individuais possam realmente ter um impacto. Mas precisamos resistir a essa reação, pois esta crise só vai ter fim se nós, como indivíduos, assumirmos a responsabilidade por esse problema. Procurando nos informar e informar os outros, fazendo a nossa parte para minimizar o consumo e o desperdício de recursos, tornando-nos mais ativos politicamente e exigindo mudanças dentre muitas outras maneiras, cada um de nós pode fazer a diferença (Gore, 2006, p. 317).

Também podemos encontrar o ideal da sustentabilidade em diversas propostas de políticas públicas que buscam a adoção de modelos econômicos e sociais amparados numa ética da sustentabilidade. No Canadá, surgiu uma das primeiras propostas de modelo de desenvolvimento com restrições ao crescimento 
econômico e incentivos ao uso mais eficiente dos recursos naturais disponíveis ${ }^{5}$. O governo holandês, por seu turno, propôs o primeiro plano nacional de orientação do desenvolvimento para ganhos qualitativos na questão ecológica ${ }^{6}$. O plano holandês prevê uma divisão considerada mais eficiente de custos privados e sociais da atividade econômica (inclusive num sentido intergeracional), supostamente penalizando o poluidor e desencorajando de várias formas o uso não sustentável dos recursos naturais. De maneira ainda mais ampla, há o reconhecimento da ONU da importância de diretrizes sustentáveis (zelo com todas as formas de vida, por exemplo), registradas na proposta conhecida como Earth Charter.

A Comissão Mundial sobre o Meio Ambiente e Desenvolvimento (CMMAD, 1991) considera que o desenvolvimento sustentável deve ser um processo capaz de harmonizar crescimento econômico, investimentos, avanço tecnológico, etc. com a exploração dos recursos e do meio ambiente em geral. Neste mesmo sentido, Sachs (1986, 2002, p. 52) afirma, baseado num critério de equidade, a impossibilidade de suspender o crescimento econômico, que "[...] deveria ser socialmente receptivo e implementado por métodos favoráveis ao meio ambiente, em vez de favorecer a incorporação predatória do capital da natureza [sic.] ao PIB". Daly (2007), por sua vez, alerta que o crescimento econômico pressupõe o emprego de recursos naturais, que só deveria ocorrer se sua utilização fosse mantida ao menos constante ou em ritmo que permitisse sua renovação. Um crescimento desta natureza seria facultado pela crescente eficiência tecnológica aliada a uma reorientação moral no sentido de produzir e consumir apenas mediante metas qualitativas definidas (Daly 2007, p. 57-59; Daly; Townsend, 1996, p. 155-157).

De acordo com Schumacher (1996a, 1996b), um nível reduzido de consumo para o atendimento das necessidades básicas parece ser um dos objetivos, cuja realização ainda é distante do tempo atual, em que a lógica do excessivo tende a comandar todos os aspectos de nossas vidas. Transformar os valores associados ao consumo é, para ele, condição sine qua non para uma sociedade sustentável. O autor recorre ao budismo e ao cristianismo (ao menos, ao seu entendimento dessas concepções teológicas) para desenvolver seu conceito de consumo consciente, baseado na simplicidade e no refreamento do "desejo por mais". Do ponto de vista ético, isso implica uma redefinição - tomando por base a formulação utilitarista da noção de bem-estar como uma condição alcançada pelo mínimo de consumo, não pelo máximo. Tal revisão (moral e ética) de valores e comportamentos e as consequentes mudanças no consumo gerariam padrões sustentáveis de uso dos recursos naturais, presumidamente invertendo as tendências atuais à degradação completa.

(5) Ontario Round Table on Environment and Economy Models Principles (Edwards, 2005).

(6) The Netherlands National Environmental Policy Plan (Edwards, 2005). 
Como se percebe, as propostas analisadas resumem-se à defesa da regulação consciente da produção capitalista, da utilização dos recursos e do consumo privado. Regulação, esta, que seria alcançada pela exortação e pela mobilização das práticas individuais no sentido ambientalmente "adequado". É bem verdade, por um lado, que essas propostas desempenham um papel importante ao expor os padrões atuais de produção, consumo, poluição e degradação ambiental. Por outro, é nítido o entendimento geral de que a reversão dessas tendências ocorreria por meio da transformação ético-moral. A defesa de uma nova ética, por conseguinte, baseia-se na crença de que a produção, ainda que submetida à lógica capitalista, seria subordinada aos desígnios de uma consciência radicalmente renovada, ecologicamente responsável, comprometida com a sustentabilidade ambiental. O slogan que sintetiza essa linha de raciocínio, enfim, é o seguinte: se refrearmos nosso ímpeto consumista e modificarmos nossos hábitos esbanjadores, todo o resto ajusta-se automaticamente.

Não parece absurdo sugerir, a partir da síntese acima, que as concepções do ecologismo acrítico fincam uma fenda que fraciona radicalmente a existência social entre a subjetividade, de um lado, e as condições objetivas, de outro. Por exemplo, jamais se questiona a relação entre os valores antiecológicos e a consciência perdulária, de um lado, e as necessidades da reprodução social, de outro. Ademais, a moral é enquadrada no campo subjetivo, como uma ideia formada de modo livre e irrestrito na consciência dos indivíduos. Trata-se, nesse caso, de um duplo equívoco: o de apartar inteiramente a objetividade e a subjetividade e o de considerar a moral algo exclusivamente subjetivo. Infelizmente, o espaço limitado do texto só nos faculta a crítica da última concepção.

\section{Lukács e os fundamentos da defesa da ética materialista}

Voltemo-nos agora para a forma como Lukács defende o caráter ontológico dos valores como a base da construção de sua ética materialista ${ }^{7}$. O ponto de partida desse argumento é a demonstração de que os valores são momentos inelimináveis das práticas humanas. Para isso, o autor examina detidamente a

(7) Uma formulação alternativa a Lukács na defesa da natureza simultaneamente objetiva e subjetiva das categorias que formam a ética pode ser encontrada em Vázquez (2007). Parece-nos, no entanto, que a análise de Lukács tem maior rigor e precisão teórica. Entre os trabalhos mais conhecidos que procuram difundir a análise de Lukács da ética, acreditamos que Lessa (2002) oferece uma interpretação bastante problemática por ter atribuído ao trabalho uma condição hierarquicamente superior no complexo da prática humana. Já em Infranca (2005), a categoria do trabalho é corretamente percebida "tão somente" como o modelo ontológico da práxis humana. A análise da relação entre o trabalho e a ética (2002, p. 126), embora igualmente acertada, situa-se num nível de abstração bem diverso do que adotamos neste artigo e semelhante àquele adotado por Tertulian (1999). Vale assinalar que Infranca também enfatiza o caráter simultaneamente subjetivo e objetivo da ética (2002, p. 128). Uma síntese do argumento de Lukács mais próxima da que apresentamos neste artigo encontra-se em Duayer e Medeiros (2007). 
forma de prática humana originária, que sedimenta (como "modelo" ontológico) todas as modalidades do agir humano: o trabalho ${ }^{8}$.

Seguindo a conhecida descrição (marxiana), Lukács (2004, p. 60) observa que o trabalho se distingue como forma de prática tipicamente humana por constituir-se em essência da objetivação de uma finalidade previamente definida, i.e., da materialização de uma ideia. Numa acepção abstrata, independente de qualquer forma histórica concreta, pode-se descrever o trabalho como a prática que procura objetivar um valor de uso ou simplesmente um valor associado à satisfação das necessidades materiais dos seres humanos. Valor de uso pode ser dito valor no sentido geral de finalidade, propósito, carecimento perseguido pela prática humana, e não no sentido específico de tempo de trabalho socialmente necessário, que é determinação específica da produção capitalista.

Lukács reconhece ainda, como Marx, que, uma vez posta a finalidade que conduz o trabalho (i.e., o valor de uso a ser produzido), é preciso que o processo de trabalho seja compatível com sua objetivação (Lukács, 2004, p. 90). Do ponto de vista ético, isso significa que o nexo entre o valor e o dever ser (a prática que deve ser compatível com a realização do valor) já se apresenta como momento indispensável do trabalho, mesmo em suas formas mais primitivas. Também esse aspecto, ou seja, o fato de envolver determinações morais (o valor e o dever ser), distingue a prática humana do trabalho (e a prática humana em geral) das atividades análogas dos animais. Na natureza, como disse Lukács, há emergências e satisfações, mas não valores (1979, p. 86, 2004, p. 143).

O trabalho, em suma, já pressupõe em seu interior, inicialmente como momentos subordinados, as categorias centrais da moral, o valor e o dever ser. $\mathrm{O}$ fato de que o valor e o dever ser sejam pressupostos do trabalho está diretamente ligado ao caráter teleológico, intencional da atividade humana. Para ser mais claro: é porque o trabalho é uma atividade destinada a realizar uma finalidade previamente definida que não apenas essa finalidade emerge como guia diretriz de todo o processo de objetivação (como ética) mas como a base do comportamento de quem trabalha (como moral) e como critério para julgar a adequação da prática (juízo de valor). Nos termos de Lukács: "toda práxis, mesmo a mais imediata e a mais cotidiana, contém em si essa referência ao ato de julgar, à consciência, etc., visto que é sempre um ato teleológico, no qual a posição da finalidade precede, objetiva e cronologicamente, a realização" (1979, p. 52).

(8) A descrição de Lukács da práxis humana a partir do trabalho é muitíssimo semelhante ao modelo transformacional do agir humano proposto por Bhaskar (1998, p. 33-37). Em ambos os casos, a análise pretende revelar propriedades da prática humana em geral a partir do trabalho, e não sustentar a superioridade do trabalho como forma de práxis. (Cf. Lukács, 2004, p. 103-104). 
É preciso, neste ponto, introduzir uma categoria fundamental na inspeção lukacsiana da práxis humana: a alternativa. O trabalho (na verdade, o agir humano), além de ser caracterizado como realização de uma finalidade preconcebida, deve ser compreendido como escolha entre alternativas concretas. Em todo ato humano, não apenas uma finalidade (valor) mas um curso de ação (dever ser) e todos os outros meios necessários a realizá-la objetivamente num mundo em si insensível com relação aos desígnios humanos são escolhidos e outros negados. (2004, p. 88-89) Reconhecer esse caráter de escolha entre alternativas permite-nos revelar, finalmente, o fundamento objetivo dos valores e, a partir deles, dos deveres ser e juízos de valor ${ }^{9}$. Abstraindo-se de todas as importantes questões relacionadas à formação da subjetividade necessária para desenvolver essa prática que elege alternativas, pode-se perceber que a própria escolha depende do fato de que o mundo contenha, em sua configuração objetiva, possibilidades ainda não explicitadas e que jamais se explicitariam a não ser pela realização bemsucedida da prática humana. Isso significa que aquilo que é afirmado ou negado como valor no interior de uma prática específica é a explicitação ou a negação de uma possibilidade do mundo reconhecida pela subjetividade humana e objetivada através da própria práxis. A conclusão é que o fundamento objetivo dos valores é a labilidade ${ }^{10}$ própria da existência tanto natural quanto social (Lukács, 1979, p. 8890).

Por outro lado, se a realização bem-sucedida da prática depende não apenas da escolha dos meios adequados mas da execução bem-sucedida (i.e., da conduta adequada), podemos reconhecer que a escolha entre alternativas também envolve o curso de ação - no trabalho, o processo de trabalho. Por conseguinte, é imprescindível que, em sua prática, os sujeitos reconheçam e escolham os cursos de ação que se ajustam à realização da finalidade posta, de início, idealmente. Com o desenvolvimento da práxis humana, as formas de conduta adequadas cristalizamse como deveres ser sociais e, nessa configuração, como a base dos juízos das práticas individuais e sociais. É exatamente com esse raciocínio que Lukács desdobra a demonstração do caráter objetivo dos valores na demonstração do caráter objetivo do dever ser e dos juízos de valor (Lukács, 1979, p. 98-99).

(9) Uma síntese deste argumento pode ser encontrada em Barroco (2008, p. 25).

(10) Segundo Lukács (2004, p. 86-97) labilidade é o termo empregado por Hartmann como sinônimo para a conhecida expressão dynamis de Aristóteles. Ambos os termos são cunhados com o propósito de reconhecer que objetos da realidade contêm em si uma série de possibilidades concretas realizáveis, mas ainda não realizadas. Por exemplo, um ser humano traz consigo a possibilidade de desenvolver-se intelectual e/ou fisicamente até certo limite. Ainda que, em muitos indivíduos, essa possibilidade não se efetive em grau representativo, ela consiste de uma determinação da existência do sujeito (não explicitada, evidentemente). Lukács considera que a dynamis aristotélica, como a labilidade de Hartmann, se situa num meio-termo entre a categoria do ser e do não ser, referindo ao que pode ser, mas ainda não é. 
Ademais, em sua análise do trabalho, Lukács, como Marx, assinala que o desenvolvimento da práxis envolve a explicitação das "potências adormecidas" na natureza humana. Esse reconhecimento da capacidade do ser humano de desenvolver (pelo condicionamento, pela educação, pelo treino) habilidades contidas na corporalidade e na subjetividade humanas, de início apenas como possibilidades, tem importância fundamental não apenas para a ética mas para a própria concepção marxiana de ser humano.

O ser humano distingue-se de todas as formas de vida por reconhecer, de algum modo, a labilidade presente em sua própria constituição biológica e desenvolvê-la pela prática, pelo agir teleológico. O momento originário desse desenvolvimento é precisamente o trabalho, e é por isso que a análise dessa modalidade de práxis se revela tão fecunda para o entendimento da especificidade do ser social. Nas palavras de Lukács:

[...] o trabalho é antes de mais nada, em termos genéticos, o ponto de partida da humanização do homem, do refinamento das suas faculdades, processo do qual não se deve esquecer o domínio sobre si mesmo. Além do mais, o trabalho se apresenta, por um longo tempo, como o único âmbito desse desenvolvimento; todas as demais formas de atividade do homem, ligadas aos diversos valores, só se podem apresentar como autônomas depois que o trabalho atinge um nível relativamente elevado (1979, p. 87).

Não se pode esquecer jamais que o trabalho é tomado aqui "simplesmente" como modelo ontológico das diferentes modalidades de prática social. As práticas humanas (inclusive a produção intelectual) são sempre atividades com condições materiais antecedentes, com condições causais, algumas das quais extraídas diretamente da natureza, outras já criadas pela atividade humana. O que fazem os seres humanos em sua prática é reconhecer nessas condições materiais a possibilidade de dar origem a algo que delas não surgiria na ausência da própria prática: o resultado previamente projetado do agir, o valor que motiva e condiciona todo o processo de realização (no caso do trabalho, o produto). Ao transformar causalidades insensíveis às finalidades humanas em "causalidades postas" por sua prática, os seres humanos criam no mundo novas formas materiais. Ao assim fazêlo, além de mudarem a própria natureza, como nos indicou Marx em sua análise do trabalho, os seres humanos abrem espaço para novas criações, para a posição de novas finalidades. Em suma, em sua prática, os seres humanos ampliam as condições objetivas e subjetivas para o reconhecimento e a posição de novas finalidades, propósitos, carecimentos. Isso quer dizer, literalmente, que modificam o campo dos valores e, por seu intermédio, dos deveres ser e dos juízos de valor. A cada estágio do desenvolvimento social, portanto, corresponde não apenas um conjunto de valores mas uma moral por eles implicada e uma forma de subjetividade (que talvez possamos chamar de ideologia). Para conhecer a moral de 
uma determinada época, deve-se descobrir os condicionantes da prática humana determinados pelo grau de desenvolvimento social. É a aplicação desse raciocínio à teoria do valor de Marx que nos permite, com base nas indicações de Lukács, desdobrá-la diretamente numa formulação (crítica) da ética idealista pressuposta no ecologismo "acrítico".

Antes de seguir adiante, é importante observar que, se o argumento de Lukács captura com correção a relação entre a moral, a prática social e as estruturas causais que constituem o mundo, então os valores do ecologismo acrítico também possuem um fundamento objetivo. Como valores legítimos da convivência social contemporânea, expressam, no plano da consciência moral, a tragédia social que acompanha contraditoriamente as conquistas dos seres humanos sobre a natureza na sociedade do capital. A questão, portanto, não é se esses valores são ou não objetivos - questão que respondemos afirmativamente. A questão é se a objetividade desses valores está ou não fundada numa contradição objetiva que torna inviável a sua realização na época atual.

\section{Marx e a ética do capital: uma brevíssima releitura}

Para extrair da análise da sociedade do capital elaborada por Marx uma concepção a respeito da moral, ou pelo menos da moral desta sociedade, é preciso partir da categoria do valor. Nesse caso, é preciso salientar que o fato de que uma mesma categoria, valor, denote simultaneamente o tempo de trabalho socialmente necessário à produção de uma mercadoria e o conjunto de objetivos (propósitos, carecimentos, projetos) que move a prática humana em geral está longe de ser pura e simples coincidência. Ao contrário, entre os autores que reconheceram o trabalho como fundamento do valor (no sentido "econômico" do termo), Marx foi quem estabeleceu de maneira mais articulada (ainda que não explícita) as implicações para a ética.

É importante retomar, nesse particular, a linha central do argumento desenvolvido pelo autor logo nos primeiros capítulos de $O$ Capital $^{11}$. Todos sabem que, para Marx, valor é trabalho (social médio), atividade social cristalizada como propriedade das mercadorias. Essa peculiaridade de o trabalho humano apresentarse como propriedade das coisas produzidas, ou de os produtos serem a "sublime objetivação de valor" (Marx, 1998, p. 74), é destacada pelo autor como uma determinação que, por si mesma, caracteriza a forma de trabalho historicamente

(11) O argumento dos próximos parágrafos é uma síntese da síntese do raciocínio dos quatro primeiros capítulos de $O$ Capital apresentada em Duayer e Medeiros (2008). Aquele texto, e agora a síntese dele, é inspirado na instigante releitura da obra proposta por Moishe Postone (1993). No que diz respeito à síntese dos argumentos de Marx (1998) apresentada nesta seção, optamos por evitar referências a passagens pontuais. Como se trata de texto muito conhecido, consideramos suficiente a simples identificação dos capítulos de $O$ Capital (os quatro primeiros). 
específica que corresponde à sociedade comandada pelo capital. Para demonstrá-lo, Marx examina os pressupostos históricos da emergência dessa forma misteriosa de objetivação do trabalho humano.

O ponto de partida do argumento é o reconhecimento de que, nos atos de troca, os sujeitos comparam, por alguma medida comum a todos os produtos, as coisas que têm em posse. Para que essa comparação entre produtos possa ser efetivada com regularidade, é indispensável que os indivíduos sejam proprietários privados das coisas comparadas. É preciso, portanto, que a propriedade privada seja a forma de propriedade dominante. Por outro lado, se a maior parte do produto social é produzida como objeto de satisfação de necessidades externas, é porque a troca já se tornou a forma dominante de distribuição dos produtos. Isso pressupõe, por sua vez, que a divisão social do trabalho seja complexa e os produtores especializados.

Se as coisas são produzidas para a troca e se a troca exige uma igualação entre as coisas produzidas com base em alguma propriedade comum à maior parte do produto social, então, é razoável supor que o trabalho, considerado abstratamente (como tempo), figure exatamente como medida dessa comparação. Afinal de contas, as coisas trocadas são qualitativamente distintas e, deixando de lado o seu caráter qualitativo diverso, só resta a propriedade comum de serem resultado do dispêndio de energia humana nos atos de trabalho. É exatamente por isso que o tempo de trabalho figura como valor das mercadorias.

É crucial salientar, finalmente, que, se o próprio trabalho, ao figurar como propriedade (valor) das mercadorias, medeia a articulação entre os sujeitos no mercado, então, pode-se afirmar que ele passa a funcionar como uma finalidade das práticas humanas: ter mais valor, ter mais trabalho (ou seus representantes, como o dinheiro ou títulos) em posse significa ter capacidade de absorver uma parcela maior da riqueza social - significa estar mais rico.

Com a elaboração teórica que acabamos de resumir, Marx consegue demonstrar que, nesta sociedade, o trabalho figura como finalidade das práticas econômicas dos seres humanos. Ademais, demonstra que essa propriedade da produção capitalista distingue não apenas a própria produção mas o capitalismo das sociedades que o antecederam ${ }^{12}$. Em todas as outras formas sociais, a não ser em circunstâncias limitadas e episódicas, o trabalho é, antes de tudo, a atividade mediante a qual os seres humanos criam, em níveis historicamente diferenciados, suas condições materiais de existência. Trata-se, então, de meio para a realização de valores, e não de finalidade, valor em si.

(12) O autor expressa claramente, já no primeiro capítulo da obra, que "o caráter social específico desse mundo é constituído pelo caráter humano geral do trabalho" (Marx, 1998, p. 89). 
Naturalmente, o trabalho preserva, na sociedade capitalista, sua condição de meio de satisfação das finalidades humanas, mas assume prioritariamente a condição de fim, de valor. É esse o sentido da reinterpretação da teoria do valor de Marx que sugerimos livremente a partir de Lukács: a teoria do valor de Marx nos revela que, em determinadas condições históricas, o trabalho, que é meio de satisfação de necessidades, emerge como fim, como valor. Aliás, o trabalho é $O$ Valor, no singular e sem qualificativos, deixando claro que se trata de uma finalidade humana que se eleva sobre todos os demais valores que movem a prática humana, subordinando-os.

No capitalismo, para reforçar, o Valor (o Valor = tempo de trabalho) subordina todos os outros propósitos humanos, subordina todos os outros valores estéticos, afetivos, religiosos, etc. - e as formas de prática correspondentes, tornando a realização desses valores por essas práticas uma determinação secundária da existência humana, como quer que elas sejam ajuizadas subjetivamente. Secundária porque, entre todas as finalidades que podem ser preenchidas pela prática de cada um dos sujeitos que vive nesta sociedade, a única efetivamente inescapável para todos é a apropriação de riqueza sob a forma de Valor.

A categoria "capital", tal como concebida por Marx, captura com precisão essa subordinação dos valores e das práticas humanas ao Valor. O autor apresenta o capital inicialmente como o valor que, em seu movimento, busca a valorização (i.e., a auto expansão). Se, nesta mesma frase, trocamos a palavra valor por seu conteúdo efetivo, trabalho, chegamos a uma expressão da categoria capital que evidencia, em seus termos, a dinâmica autocentrada do trabalho na formação social capitalista: capital $=$ valor que, em seu movimento, busca a expansão; ou seja, = trabalho que, em sua dinâmica, busca a expansão.

É o caráter autocentrado da dinâmica do trabalho que caracteriza a forma de subordinação correspondente à sociedade capitalista ${ }^{13}$. O trabalho desta sociedade tem uma configuração estrutural, surgida espontaneamente das ruínas da sociedade feudal, da qual emana um movimento dinâmico no sentido da sua própria expansão. Uma vez que essa dinâmica autocentrada do trabalho - o "sujeito automático" [automatisches Subjekt] de que falava Marx (1998, p. 184) - é movida, como tudo mais que ocorre na sociedade, pela prática de indivíduos concretos, é preciso que todos os pressupostos dessa prática estejam em conformidade com sua reprodução (a reprodução da dinâmica).

(13) Diversos autores destacaram, na leitura de Marx, esse momento do argumento como o elemento central de sua análise crítica da sociedade burguesa. Dentre eles, podemos destacar Kurz (1992), Postone (1993) e Mészáros (2002). 
Entre esses pressupostos, encontram-se não apenas as condições materiais das práticas humanas (as causas materiais aristotélicas) e o conhecimento necessário para conciliar meios e fins mas os próprios fins, os valores previamente concebidos em torno dos quais gira a prática humana. Ao converter-se na principal finalidade das práticas humanas, o trabalho cria as condições subjetivas para que a dinâmica autocentrada do trabalho movimente-se pelo agir dos indivíduos. Forma-se, assim, a moral compatível com a dinâmica incontrolável do trabalho em expansão. É exatamente isso que Marx quis dizer em sua análise do fetichismo da mercadoria. O trabalho, embora seja produto de nossas práticas, adquire uma dinâmica própria, estranhada, que nos coage, nos subordina. É sobre essa dinâmica que se ergue a formação social em que vivemos, "uma formação social em que o processo de produção domina o homem, e não o homem o processo de produção" (Marx, p. 103). Podemos, finalmente, concluir que, para Marx, a sociedade do capital é, na verdade, a sociedade do trabalho estranhado (capital) e de sua moral. Como em toda moral, a moral do capital envolve um conjunto de deveres ser. Como sempre, o dever ser correspondente depende da condição particular em que se encontram os indivíduos concretamente existentes. No caso da sociedade capitalista, a condição de classe, por ser determinante direto da condição econômica particular dos indivíduos, torna-se o elemento fundamental na determinação do dever ser correspondente à realização do Valor. Para a classe trabalhadora, a realização do Valor exige o comportamento adequado ao aproveitamento pelo capital (ou seja, o enfrentamento da concorrência entre os trabalhadores no mercado de trabalho). Para a classe capitalista, exige-se o comportamento adequado para a reprodução ampliada (concorrência entre capitais) ${ }^{14}$.

É importante frisar que os valores e as práticas dos sujeitos das duas classes são subordinados ao capital (ao Valor), embora as condições de subordinação sejam distintas e, no geral, obviamente mais favoráveis para a classe capitalista. Sejam quais forem as condições de subordinação, o fato é que trabalhadores, ocupados ou não, capitalistas, rentistas, ricos e pobres, a ninguém, nesta forma de sociedade, é dado o direito ou a liberdade de se opor ao movimento dinâmico do capital, sob a pena da perda da condição social e, no limite, física. Para Marx, livrar-se dessa subordinação exige livrar-se do capital. Ou seja, livrarse do Valor. Ou seja, livrar-se do trabalho sob a forma capitalista (e não da forma de trabalho capitalista). E, portanto, da ética do trabalho que subordina o comportamento dos sujeitos (todos os valores, de todos os sujeitos) na sociedade em que vivemos.

(14) No interior de cada classe, condições particulares de ocupação, qualificação, condições físicas e mesmo genéticas dão contorno final ao tipo de comportamento adequado (útil, eficiente, bom, etc.) ao aproveitamento pelo sujeito automático. 


\section{Conclusão}

Se nossa interpretação de Marx é cabível e, de fato, a sociedade capitalista envolve a subordinação da moral e da ética ao Valor (trabalho), então os valores que constituem a ética implícita ao ecologismo acrítico não podem escapar a essa subordinação. Considerando que as teorias que dão forma ao ecologismo acrítico recebem o qualificativo "acrítico" justamente porque sequer tematizam a possibilidade de superação histórica da sociedade capitalista - considerando, portanto, que a sociedade do Valor é admitida a priori -, então a possibilidade de realização objetiva da assim chamada ética ambiental é determinada pela sua relação com a realização do Valor. Se essa "ética ambiental" envolve práticas que impedem ou contradizem a reprodução ampliada do Valor, ela é, a não ser em âmbitos restritos e limitados, insustentável - para empregar o jargão da área.

Demonstrar essa insustentabilidade requer uma investigação rigorosa e extensa das condições de realização dos valores que dão forma aos anseios (autênticos ou forjados) de transformação radical da relação entre os seres humanos e o ambiente. Em nosso artigo, não assumimos essa demonstração como objetivo, nem poderíamos tê-lo feito. Ao contrário, procuramos aqui inverter a lógica do raciocínio crítico e demonstrar que, na verdade, o ecologismo acrítico parte de um pressuposto que sustenta todo o edifício teórico (e confere legitimidade às práticas correspondentes): que a realização dos valores da "ética ambiental" é compatível com a realização do Valor que subordina a ética e a moral na sociedade do capital.

Não é absurdo imaginar que a objetivação da "ética ambiental" exija uma brutal e custosa transformação da produção, do consumo, da estrutura urbana, das habitações, do sistema de transportes, de todos os contornos da vida social, enfim. Se é assim, parece claro que o ônus da prova cabe aos que, explícita ou veladamente, postulam a compatibilidade entre esse extenso conjunto de práticas e a preservação da categoria que, não por acaso, distingue a forma social em que vivemos: o capital.

\section{Referências bibliográficas}

BARROCO, M. H. Ética: fundamentos sócio-históricos. São Paulo: Cortez Editora, 2008.

BHASKAR, R. The possibility of naturalism. Brighton: Harvest, 1998.

BURKETT, P. Marx and nature: a red and green perspective. New York: St. Martin's Press, 1999.

CMMAD - Comissão Mundial sobre o Meio Ambiente e Desenvolvimento. Nosso futuro comum. Rio de Janeiro: Editora da Fundação Getúlio Vargas, 1991.

COASE, R. The problem of social cost. The Journal of Law and Economics, n. 3, p. 1-44, 1960. 
COSTANZA, R. et al. The value of the world's ecosystem services and natural capital. Nature, v. 387, p. 253-260, May 1997.

DALY, H. Ecological economics and sustainable development. Selected essays of Herman Daly. Northampton: Edward Elgar Publishing, Inc., 2007.

; TOWNSEND, K. Valuing the earth: economics, ecology, ethics. Cambridge: MIT press, 1996.

DUAYER, M.; MEDEIROS, J. L. Marx, estranhamento e emancipação: o caráter subordinado da categoria da exploração na análise marxiana da sociedade do capital. Revista de Economia, Curitiba, Editora da UFPR, v. 34, p. 151-161, 2008. . 'Under-labouring' for ethics: Lukács's critical ontology. In:

LAWSON, C. et al. Contributions to social ontology. Oxon: Routledge, 2007.

EDWARDS, A. The sustainability revolution. Canada: New Society Publishers, 2005.

FONTES, V. Capitalismo, exclusões e inclusão forçada. Revista Tempo, Rio de Janeiro, UFF, v. 2, n. 3, 1996.

FOSTER, J. B. Ecology against capitalism. New York: Monthly Review Press, 2002.

GORE, A. Uma verdade inconveniente. São Paulo: Editora Manole, 2006.

GREENPEACE. How to save the climate. 2007. Disponível em: www.greenpeace.org/raw/ content/international/press/reports/how-to-save-the-climate-pers.pdf.

HOTELLING, H. Letter to the Director of the National Park Service. In: PREWITT, R. A. The economics of public recreation. The Prewitt Report. Washington DC: Department of the Interior, 1949.

INFRANCA, A. Trabajo, individuo, historia: el concepto de trabajo en Lukács. Buenos Aires: Ediciones Herramienta, 2005.

KURZ, R. O colapso da modernização: da derrocada do socialismo de caserna à crise da economia mundial. Rio de Janeiro: Paz e Terra, 1992.

LESSA, S. O Mundo dos homens: trabalho e ser social. São Paulo: Boitempo, 2002.

LUKÁCS, G. Ontologia do Ser Social - Os princípios ontológicos fundamentais de Marx. São Paulo: Lech, 1979.

. Ontología del ser social - El trabajo. Buenos Aires: Herramienta, 2004.

MARX, K. O capital: crítica da economia política. Rio de Janeiro: Civilização Brasileira, 1998.

MÉSZÁROS, I. Para além do capital: rumo a uma teoria da transição. São Paulo: Boitempo Editorial; Campinas: Editora da Unicamp, 2002.

NETTO, J. P. Georg Lukács: um exílio na pós-modernidade. In: PINNASSI, M. O.; LESSA, S. (Org.). Lukács e a atualidade do marxismo. São Paulo: Boitempo, 2002. 
PEARCE, R.; TURNER, R. Economics of natural resources and the environment. Baltimore: The John Hopkins University Press, 1990.

POSTONE, M. Time, labor, and social domination: a reinterpretation of Marx's critical theory. Cambridge: Cambridge University Press, 1993.

SACHS, I. Ecodesenvolvimento: crescer sem destruir. São Paulo: Vértice, 1986.

- Caminhos para o desenvolvimento sustentável. Rio de Janeiro: Garamond, 2002.

SCHUMACHER, E. F. The age of plenty: a Christian view. In: DALY, H.; TOWNSEND, K. Valuing the earth: economics, ecology, ethics. Cambridge, MA: MIT Press, $1996 \mathrm{a}$.

Buddhist economics. In: DALY, H.; TOWNSEND, K. Valuing the earth: economics, ecology, ethics. Cambridge, MA: MIT Press, 1996b.

SMALL, B.; JOLLANDS, N. Technology and ecological economics: Promethean technology, Pandorian potential. Ecological Economics, v. 56, p. 343-358, 2006.

SMITH, G. A. The purpose of wealth: a historical perspective. In: DALY, H.; TOWNSEND, K. Valuing the earth: economics, ecology, ethics. Cambridge, MA: MIT Press, 1996.

SOLOW, R. Is the end of the world at hand? In: GILL, R. T. (Ed.). Great Debates in Economics, v. 1, 172-180. Pacific Palisades, CA: Goodyear, 1976.

STERN, N. The economics of climate change: the Stern review. Cambridge: Cambridge University Press, 2007.

TERTUliAn, N. O grande projeto da ética. Ad Hominen 1, I, São Paulo, 1999.

VÁZQUEZ, A. S. Ética. Rio de Janeiro: Civilização Brasileira, 2007. 